Sociohistórica, $n^{0}$ 40, e039, 2do. Semestre de 2017. ISSN 1852-1606

Universidad Nacional de La Plata.

Facultad de Humanidades y Ciencias de la Educación.

Centro de Investigaciones Socio Históricas

\title{
Historizar las memorias. Diálogos, conflictos y legitimidades en torno al pasado reciente
}

\author{
Reseña de: Elizabeth Jelin, La Lucha por el pasado: Cómo construimos la \\ memoria social. Buenos Aires, Siglo XXI Editores, 2017, 302 pág.
}

\author{
Victoria Estermann *; Nicolás Herrera **; Melina Jean Jean ***
}

* Centro de Investigaciones Socio-históricas CISH, Instituto de Investigaciones en Humanidades y Ciencias Sociales (Facultad de Humanidades y Ciencias de la EducaciónUnivercidad Nacional de La Plata), Argentina |vickyestermann_91@hotmail.com

** Centro Interdisciplinario de Metodología de las Ciencias Sociales CIMeCS, Instituto de Investigaciones en Humanidades y Ciencias Sociales (Universidad Nacional de La Plata/CONICET) y Facultad de Humanidades y Ciencias de la Educación (Universidad Nacional de La Plata), Argentina | herreranicolas@hotmail.com

*** Centro de Investigaciones Socio-históricas CISH, Instituto de Investigaciones en Humanidades y Ciencias Sociales (Universidad Nacional de La Plata-CONICET), Argentina I melinajeanjean@hotmail.com

Al interior de la extensa producción académica elaborada por Elizabeth Jelin sobre la construcción social de memorias, La lucha por el pasado podría ser pensado -al menos así lo señaló la propia autora $^{1}$ como el libro que cierra una etapa de su trayectoria intelectual. Sin embargo, cabría preguntarse si este es un libro donde dicha trayectoria es interrogada, mirando hacia atrás, con el objetivo de elaborar un balance sobre lo producido a lo largo de tres décadas ¿ $\mathrm{O}$ en realidad es un texto que, como su objeto -las memorias sociales ligadas a procesos políticos violentos-, construye desde el presente una narrativa sobre el pasado en la cual su orientación de futuro es absolutamente innegable? Es justamente ahí, en esas temporalidades socialmente construidas (entre pasado, presente y futuro) donde se ubica el leitmotiv del libro: exponer y analizar la historicidad de esas memorias.

Sin lugar a dudas una de las particularidades del libro es el tono de su escritura y el tipo de 
materiales con los cuales está elaborada. El tono personal -por momentos autobiográfico- y una "escritura híbrida, entre lo académico, el compromiso cívico-político y mi propia subjetividad” (p.13) le otorgan a este libro un carácter singular dentro de la producción académica de su autora. Cabría agregar que, además de personal e híbrido, el libro es producto de un proceso de reescritura -y por lo tanto un ejercicio de resignificación- sobre algunos de los textos centrales que Jelin publicó a lo largo de las últimas tres décadas. Y como toda re-interpretación del pasado el libro repone aquellos textos quitando antiguos elementos y agregando otros nuevos. Por su parte, el marco dentro del cual se inscriben temáticamente los ocho capítulos que lo componen podría ser resumido señalando que si el pasado es algo determinado -no puede cambiarse-, serán los sentidos otorgados desde el presente los que finalmente se constituirán en objeto de diálogo y disputa. Dentro de ese marco temático, centrado en la experiencia argentina desarrollada desde los años setenta del siglo XX -pero no agotándose allí $\underline{2}$ cada uno de los capítulos está centrado en caracterizar a los actores intervinientes en el campo de las memorias y analizar sus estrategias de confrontación, negociación, alianza y enfrentamiento: movimientos de derechos humanos, el Estado, testigos y víctimas del terrorismo de estado, académicos, artistas, etc.

\section{Un recorrido por los temas de cada capítulo}

En el primer capítulo, “La conflictiva y nunca acabada mirada sobre el pasado”, la autora ubica los procesos de construcción de memorias regionales dentro de una perspectiva global. El punto de partida es el tropo a partir del cual ellas devinieron, el surgimiento de la memoria como fenómeno cultural y político y las reflexiones sobre cómo elaborar y dar sentido al pasado: la Segunda Guerra Mundial y las atrocidades del régimen nazi. Historizando estas memorias Jelin propone pensar algunos elementos de la historia alemana para luego adentrarse en las experiencias dictatoriales que atravesaron distintos países del Cono Sur como Chile, Uruguay, Brasil, Paraguay y, en particular, la Argentina. Desde allí analiza las formas en que nuestra sociedad y el Estado democrático confrontaron sus pasados violentos hasta nuestros días.

En el segundo capítulo, "La conformación de un campo de investigación“, Jelin cambia de foco para "encuadrar y comprender” (p.24) el surgimiento de los estudios de la memoria y el género dentro del campo académico latinoamericano; planteado la existencia de un desarrollo convergente e interrelacional entre ambos. Asimismo, es el capítulo donde más claramente se expresa el carácter autobiográfico de la obra: al analizar estos campos la autora realiza un balance de su propia producción y de cómo se fueron desarrollando estas temáticas en el continente. Una de las características que la autora destaca es que la relación entre el movimiento de derechos humanos, las investigaciones sobre la memoria del pasado reciente y el feminismo no han sido armónicas, sino que estuvieron cargadas de tensiones. En esta línea señala la importancia de los movimientos sociales y su capacidad de instalar agenda para el desarrollo de los estudios académicos.

En “Certezas, incertidumbres y búsquedas”, el tercer capítulo, Jelin analiza de manera dialógica la conformación, continuidades y transformaciones del movimiento de derechos humanos -durante el golpe de Estado de 1976 y la posdictadura- y la construcción democrática en Argentina. Posicionándose como demandantes frente al Estado y también como emprendedores y promotores de la acción estatal, el movimiento y los derechos humanos (como marco y discurso legítimo) fueron fundantes de la naciente democracia argentina. La autora analiza sus luchas e iniciativas 
hasta mediados de los ochenta: acciones dedicadas a la contención de las víctimas y familiares, difusión de información, organización de redes de solidaridad a nivel internacional. Y fundamentalmente, las denuncias y demandas de "verdad” y “justicia”. En adelante, a éstas se incorporaron la memoria (contra el olvido y la impunidad). Así, la autora realiza un recorrido por los diferentes planos, sentidos y temporalidades de la transición, destacando particularmente el vínculo del movimiento con los sucesivos gobiernos constitucionales y las tensiones que, por su parte, evidenciaron los límites de la unidad del movimiento y sus diferencias internas.

En el cuarto capítulo, “Marcar para recordar”, la autora aborda otros planos de acción de los actores sociales y el Estado. Se trata de las demandas y políticas de memorialización: fechas, rituales y prácticas de conmemoración, marcas territoriales, recuperación y digitalización de archivos. Estas manifestaciones públicas en el Cono Sur y en particular Argentina, se tradujeron en luchas sociales y políticas. En iniciativas propias de los actores o “emprendedores” en juego (p. 163) y en respuestas estatales al reclamo de reconocimientos y reparaciones simbólicas a través de materialidades y materialización de las memorias. De esta forma, recorriendo algunos casos, Jelin analiza los nexos entre el pasado y el presente, y las luchas por los sentidos y legitimidades de quienes recuerdan, qué recuerdan, cómo recuerdan y para quienes recuerdan.

Si bien a lo largo de todo el libro se encuentra presente el interés por transversalizar la perspectiva de género, es en los capítulos cinco y seis donde la autora trata específicamente la temática como un eje central. En el quinto capítulo, “¿Víctimas, familiares o ciudadanos?” se aborda la idea del vínculo sanguíneo y de la experiencia vivida de las víctimas. La idea de familia estuvo presente en los discursos durante la dictadura. Por un lado, en el discurso castrense, el sentido de Nación como la “gran familia argentina”. Por el otro, en la oposición, la idea de “lazo familiar” que generó legitimidad en las madres al momento de llevar adelante las protestas contra el régimen. La autora reflexiona sobre la priorización de la voz de los familiares y afectados directos, la cual instala voces “más legítimas que otras”. Así, la exclusión de toda persona no afectada directamente puede conllevar una monopolización de la "verdad” por parte de los actores directamente afectados.

En "Los abusos sexuales como crímenes de lesa humanidad y el respeto a la intimidad", el sexto capítulo, la autora se enfrenta al abordaje de las violaciones y los abusos sexuales sistemáticos en la dictadura. Uno de los dilemas que comenzaría a surgir sobre esta dimensión del terrorismo de Estado fue, justamente, cómo narrarla, tanto por el contexto en el que se daban las denuncias como en relación a los marcos interpretativos. La visibilización de esta temática enfrentó luego un doble desafío. Por un lado, el de poder escuchar los testimonios que se expresaban desde un "lenguaje femenino”, y por el otro, evitar una exposición innecesaria, permitiendo la reconstrucción de aquella privacidad que había sido rota por la experiencia de la tortura. El cruce entre una perspectiva de género y los estudios de la memoria se vuelve fundamental en los análisis del capítulo.

El séptimo capítulo, “Tomar la palabra”, está dedicado a analizar a nivel microsocial e incorporando la subjetividad de los actores, el lugar del testimonio en la historia de las memorias. Es tal vez aquí donde el eje que atraviesa el libro (las temporalidades y la historicidad de las memorias, reiteramos) sea expuesto con mayor profundidad: la autora analiza las múltiples temporalidades que se encuentran involucradas en las narrativas testimoniales estableciendo una diferencia entre los 
contextos en que esos testimonios son elaborados y los tiempos a los cuales los mismos hacen referencia. Y si el análisis de esta doble temporalidad no fuera suficientemente complejo, la misma es vinculada con los tiempos del devenir histórico y el transcurso del tiempo biográfico. A la par de esta preocupación Jelin se pregunta por el carácter problemático de la noción de testigo, específicamente por la de testimonio. ¿Qué es un testimonio? Los sobrevivientes del terrorismo de estado, sus familiares, compañeros y compañeras han elaborado una narrativa sobre el accionar represivo del Estado que permitió reconstruir oralmente -proceso especialmente útil cuando no quedaron rastros documentales- "la verdad de lo ocurrido". Sin embargo el testimonio es mucho más que la posibilidad de transmitir y reconstruir una información fáctica: al expresar una voz singular constituye un instrumento de reconstrucción de la propia identidad del testigo. Testimonio que precisa de una escucha específica para constituirse plenamente; aquella que soporte sus recuerdos y sus olvidos, sus palabras y sus silencios.

Finalmente, en “Memoria, ¿Para qué?”, la autora analiza la relación entre memoria y democracia. En ese marco temático firma que las prácticas de recordación no solo estuvieron dominadas por un mandato/deber de memoria sino que además, con el correr de los años, dicho mandato/deber se constituyó en un supuesto básico que orientó las prácticas de los actores intervinientes en este campo. En tal sentido Jelin se pregunta si la existencia de una política activa de memoria es condición necesaria para la construcción democrática, señalando que ese imperativo ético (el deber de memoria) se volvió una certeza para dichos actores, un eslogan que muchos dieron (y aún dan) por sentado. Si el tratamiento institucional de ese pasado no perjudica el desarrollo democrático, la provocadora interrogación que la autora lanza refiere a pensar qué aspectos del tratamiento de ese (y solo ese) pasado benefician la ampliación y el desarrollo del sistema democrático.

\section{Conclusiones: un conjunto de interrogantes abiertos}

El nuevo libro de Jelin provoca, y lo hace en varios sentidos. Partiendo de la forma y el tono de su escritura, pasando por un balance crítico sobre el campo de los estudios de las memorias, y terminando con preguntas incisivas sobre la relación entre derechos humanos y democracia. Análisis que irrumpen en un presente donde los derechos humanos no constituyen únicamente un “imperativo ético" a defender, sino un campo de nuevas disputas. No quisiéramos cerrar esta reseña sin dejar abiertas algunas de las reflexiones que nos despertó la lectura del libro. La primera refiere a la transversalización del género -en tanto perspectiva analítica y metodológica- en la producción de un texto académico. Si bien la autora hace un excelente trabajo al vincular género y memorias, asume la dificultad que tuvo a la hora de redactar la totalidad del trabajo desde dicha perspectiva. En tal sentido nos preguntamos cómo podríamos realizar una transversalización de la perspectiva de género en nuestras producciones escritas, de una forma integral y sin que la misma quede forzada o desacoplada en los distintos apartados de un mismo texto.

La segunda reflexión parte de la afirmación que realiza Jelin respecto a que la expresión "derechos humanos" quedó fijada a los reclamos de memoria, verdad y justicia que distintos actores desarrollaron ante las violaciones cometidas por la última dictadura militar. Si asumimos que la noción de derechos humanos es mucho más amplia, esa fijación termina siendo problemática para la ampliación y la profundización democrática. En este marco la autora se pregunta "bajo qué 
condiciones la atención prestada a la memoria de las dictaduras ayuda u obstruye la aceptación social y estatal de una concepción amplia de los derechos humanos, que incorpore una perspectiva universal de derechos civiles y políticos, pero también económicos, sociales y culturales, individuales y de incidencia colectiva” (p. 274, cursivas nuestras). Esta pregunta no solo es provocativa a nivel intelectual sino sumamente incisiva en nuestra coyuntura política: mientras la reciente desaparición forzada de Santiago Maldonado logra articular a amplios sectores de la sociedad en una demanda hacia el Estado, las demandas por las recurrentes violaciones a los derechos humanos sufridas por los pueblos originarios parecen quedar en un segundo plano. En tal sentido, coincidimos con Jelin cuando afirma que fijar la defensa por los derechos humanos con el terrorismo de estado podría limitar las posibilidades de incluir a otros actores y articular sus demandas hacia el Estado, construyendo una ciudadanía (aún más) amplia, activa, comprometida y con fuertes convicciones democráticas.

\section{Notas}

1 Al iniciar su alocución en la presentación del libro realizada en el Rectorado de la UNLP el 12 de septiembre del 2017, la autora señaló: "Para mí este libro es cerrar una etapa. Estoy un poco cansada, llevo muchos años en este tema, son más de treinta años”.

$\underline{2}$ El libro dialoga con otras experiencias latinoamericanas (Chile, Uruguay, Paraguay y Brasil) y europeas (Alemania, Italia, Francia y España). 